\title{
Influence of Selected Diagnostic Parameters on the Quality of AWJ Cutting Surface
}

\author{
Tomasz Wala' ${ }^{1}$ Krzysztof Lis ${ }^{1}$ \\ 1 Faculty of Mechanical Engineering, Department of Machine Technology, Silesian University of Technology in \\ Gliwice, ul. Konarskiego 18A, 44-100 Gliwice, Poland \\ * Corresponding author's e-mail: tomasz.wala@polsl.pl
}

\begin{abstract}
The article presents a review of research methods for the cutting process using the abrasive waterjet machining. The focus was on assessing the possibility of monitoring the cutting process based on the parameters available for direct or indirect measurement. An attempt was made to evaluate their influence on the machined surface after treatment with the abrasive cutting method. These parameters include, inter alia, vibrations of the cutting head, force effects on the head support structure and the material to be cut, dynamic properties of the machine support structure and high pressure pumps. As part of the own research, correlation was sought for the registered selected signal characteristics with the cutting parameters responsible for the process course and the parameters related to the obtained machined surface. For this purpose, a model of the deflection angle of the abrasive waterjet was proposed, which qualitatively determines the condition of the surface after cutting. The angle of inclination of the abrasive waterjet is determined on the basis of the registration of the feed force during the cutting process. The research on surface topography was extended by an attempt to determine the surface roughness by measuring vibrations and looking for correlation between the displacements of the cutter head tip and the measured roughness height profile. These tests also allowed the identification of selected frequencies that clearly result from the set parameters of the cutting process. The last stage of the research was to monitor the cutter head behaviour using a deformation sensor as another concept for recording the forces during the cutting process. Finally, the proposed methodology was characterized in the context of its usefulness in the on-line process monitoring and supervision system.
\end{abstract}

Keywords: waterjet machining, quality machine surface, monitoring AWJ process.

\section{INTRODUCTION}

One of the requirements for ensuring high cutting standards with high-pressure waterjet cutting technology is continuous real-time process monitoring to ensure process stability. In this regard, numerous experimental studies on process monitoring are currently being carried out, leading to even more advanced process monitoring.

In order to make a correct conclusion on the basis of the monitored physical quantities related to the cutting process with the cutting quality parameters, it is first necessary to define the relationship between the input parameters affecting the cutting process and the output parameters describing the cutting effects. Figure 1 shows which parameters of the water-jet cutting process influence the cutting effects, as determined by Swaroop et al. [1].

The effect of increasing the diameter of the focusing tube will be an increased flow rate of the pumped water in order to keep the pump pressure constant. As a result, the automatic control system of the high pressure pump will react with a higher frequency of piston movement in the multiplier. Thus, there will be an increase in the frequency of pulsations in the water jet which, despite the use of a high-pressure accumulator compensating ripples of water pressure, is visible in fluctuations of water pressure feeding the cutting head.

An increase in abrasive parameters will affect the parameter of mixing efficiency of the abrasive 


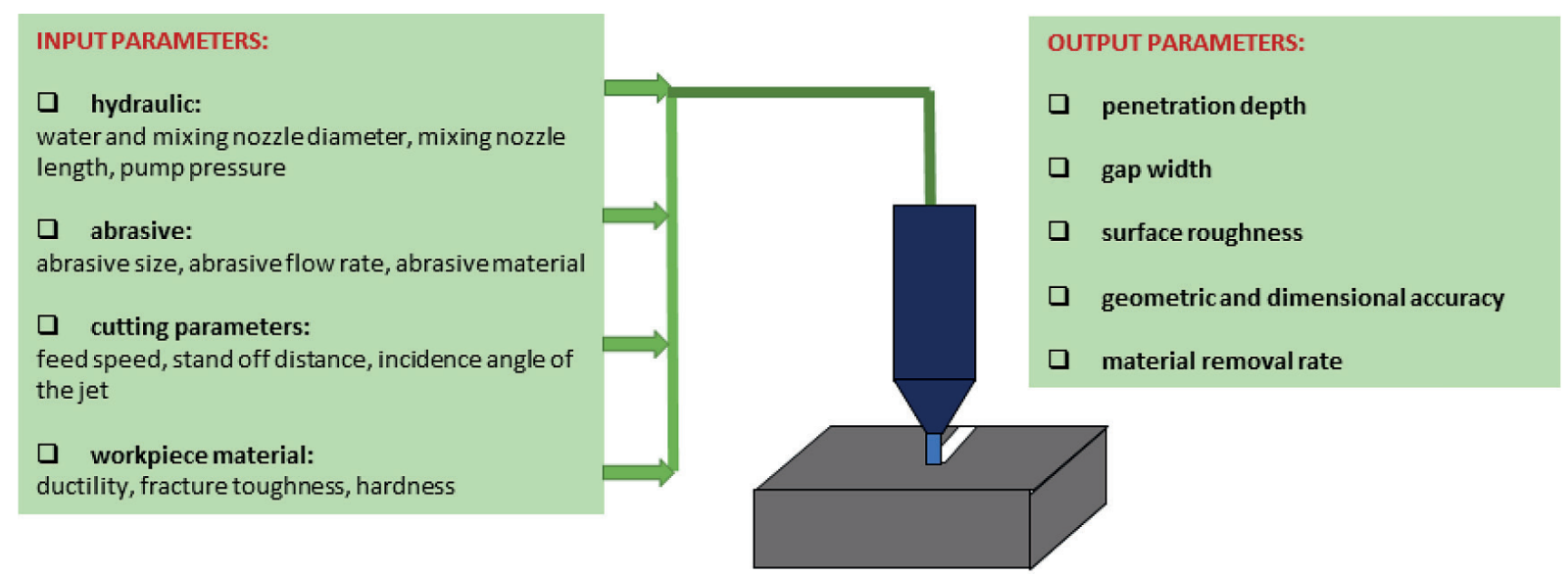

Fig. 1. Parameters of the waterjet abrasive cutting process [1]

and water in the cutter head, but also increase the cutting efficiency of the workpiece. An increase in cutting efficiency will contribute to a decrease in the jet deflection angle and thus a decrease in the value of force actions in the direction of the axis of the cutting head $\left(F_{h}\right)$ and in the direction of the feed $\left(F_{f}\right)$ will decrease. An increase in the feed speed of the cutter head along the cutting contour contributes to an acceleration of the cutting process, whereby an increase in speed will increase the deflection angle of the cutting stream. This factor will also increase the force actions in both the cutter head axis direction and the feed direction. The mechanical properties of the workpiece material will primarily affect the rate and method of material removal. With softer materials the cutting process will be more favourable from the point of view of material removal rate in the cutting line. This will contribute to a reduction in the value of force interactions. It should be noted, however, that the jet exiting the focusing tube expands very quickly, increasing its diameter. When cutting soft materials, this will cause a gap convergence effect, where the width of the gap will increase with increasing penetration depth. It is obvious that an increase in material hardness will result in an increase in force effects due to increased jet deflection, which can be compensated for by changing the input parameters e.g. increasing pump pressure or decreasing feed rate.

Therefore, it becomes possible to adjust the input values of the cutting parameters, which can be done precisely by measuring the force interactions.

Measurement of the vertical cutting force $F_{h}$ in water abrasive machining shows that it changes due to changes in cutting parameters such as pressure, focusing tube diameter, distance of the orifice mouth from the workpiece surface and abrasive flow rate as pointed out in article of Kovacevic [2]. The force will increase as the pressure and flow rate of the abrasive increases, while the force will decrease when the focusing tube is worn, the distance of the orifice mouth from the workpiece surface increases.

At present, the area of parameter monitoring, in terms of maintaining the stability of the process related also to quality control, is in the sphere of research, but the results give promising results, which in the future may allow the construction of a cutter head with advanced monitoring of the cutting process.

Measurement of vibrations of cutting process components can be used to identify dynamic phenomena occurring in the process. These are created, for example, by the action of the waterjet or abrasive waterjet which changes as a result of changes in the cutting conditions. Such measurement is possible using, for example, a vibration acceleration sensor. Due to the complex distribution of cutting forces, the value of these forces can be recorded individually for each axis of the determined Cartesian coordinate system. Lin et al. [3] explained that the interactions which occur during the cutting process can be divided into dynamic and static. However, the mechanism of generating these interactions is different.

Dynamic actions contain information about the direct interaction of the abrasive waterjet with the cut object. They carry information about the degree of constancy of the cutting conditions mainly in relation to the high pressure waterjet generation process. This information includes, for example, pressure pulsation and mixing conditions of the abrasive in the mixing chamber. The measurement of pressure pulsation makes it possible to monitor the degree of wear of the pump 
with respect to leaks that occur and also provides information about the constancy of the parameters during the long-term operation of the pump. Measurement of the abrasive flow rate helps to monitor the degree of mixing of the abrasive with the water and the quantity of abrasive fed into the process. The variation in loads also clearly indicates changes in cutting conditions due to deflection effects of the cutting jet during the cutting, where in critical cases the workpiece may be undercut along its thickness.

Static loads, on the other hand, provide information on how efficient the cutting process is. They measure the axial force $F_{h}$ and the feed force $F_{f}$ and depend on the deviation of the abrasive waterjet. This deviation can depend on parameters such as feed rate, pressure, hardness of the material being cut, abrasive flow rate. Also, the wear process of the focusing tube can be monitored over a specified long period of time.

Carah et al. [4] performed a study the effect of changing the diameter of the focusing tube on the surface roughness on the example of machining rotating workpieces. It has been pointed out that an increase in the diameter of the focusing tube results in faster disintegration of the abrasive waterjet as the distance from the orifice mouth increases. It has been pointed out that an increase in the diameter of the focusing tube reduces the amount of abrasive per volumetric unit, which again affects the machining time.

Copertaro et al. [5] presented the idea of mounting the accelerator sensors (PCB 352C34 ICP ceramic) using a special adapter, in which two sensors were placed relative to each other at an angle of 90 degrees in the plane parallel to the surface of the workpiece and one sensor in the axis of the cutting head. It was noted that the relevant parameter which best represents the nature of the cut is the value of the recoil force acting in the axis of the cutter head. The authors of the study defined the ranges of frequencies tested called the low range in the range of 500 $\mathrm{Hz}$ to $10 \mathrm{kHz}$ and the high range in the frequency range of $10 \mathrm{kHz}$ to $50 \mathrm{kHz}$. It was pointed out that the $10-500 \mathrm{~Hz}$ range does not bring significant information about the process. Kovacevic et al. [6] proved that in the low frequency range, the greatest influence on vibrations comes from the waterjet, while abrasive particles are responsible for vibrations above $10 \mathrm{kHz}$. In the research presented in [5], an index called the power index was determined, for which a strong linear correlation with the power of the waterjet was proven. This index helps to control stability by adjusting the pump pressure parameter and the abrasive flow rate. During the research it was pointed out that the behaviour of the cutting head in terms of jet power can also be influenced by the way the entire head assembly is mechanically connected.

Hassan et al. [7] pointed out that the value of the vertical cutting force $F_{h}$ varies with the depth of cut, where the depth of penetration of the abrasive waterjet is reflected by an increase in the vertical force. This conclusion may allow the control of parameters during the cutting process, when there is a case of cutting a workpiece with different thicknesses or workpieces of heterogeneous material. In the same article it was pointed out that measurements of signals using an acoustic emission sensor carry additional information about the cutting process. The variation in the energy bandwidth of the acoustic emission signal is strongly influenced by the applied pressure during the cutting. The energy level is significantly higher for higher pressures than for lower pressures. It has been noted that the response of the acoustic emission sensor when changing the depth of cut is much more sensitive than when measuring the cutting force response. Thus, the depth of cut can be easily estimated by measuring the AE energy level during the actual cut. Therefore, an alternative approach could be to use $\mathrm{AE}$ sensors to monitor the depth of cut.

An interesting study is presented by Valíček at al. [8], where the authors searched for a relationship between noise in the water jet cutting process and the surface roughness obtained. Here the measurement of the level of acoustic emission was used for automatic regulation of the cutting head feed speed as the main parameter responsible for the surface quality. Very similar research in the area of quality control of the water jet cutting process was presented by Peržel et al. [9], where PCB IMI type 607A11 sensors placed on the workpiece along the cut were used. The authors pointed out that an accurate analysis of the quality and surface roughness, their identification and then juxtaposition of individual vibration waveforms with pre-runs obtained using an acoustic emission sensor can be a useful source in quality control during the cutting. It has been observed that during the analysis of the vibration spectrum, an increase in the abrasive intensity parameter causes a decrease in the amplitude in the frequency range of $12.5 \mathrm{kHz}$. 
Jurisevic et al. [10] performed a study was performed using sound emission measurement to control the abrasive waterjet machining process in the area of maintaining a constant distance between the tip of the orifice mouth and the surface of the workpiece, where the upper surface may not always be at the same level. The results and analysis of the research showed that an increase in the distance of the orifice mouth influences an increase in the frequency of the sound generated.

\section{MEASUREMENT OF FORCE INTERACTIONS DURING THE ABRASIVE WATERJET PROCESS}

The water abrasive machining parameters, from the hydraulic parameters to the abrasive parameters, but also the properties of the material being cut, influence the distribution of the reaction forces measured at the contact of the cutting jet on the cutting face as well as on the cutting surface. The distribution of the forces defined at a point lying on the tangent of the cutting face is shown in Figure 2.

The force $F_{\mathrm{f}}$ should be as low as possible from the point of view of the best possible surface roughness and orientation of the characteristic trace of the waterjet cutting (striations). Increasing its values may indicate an increase in the waterjet deflection and thus an increase in the cutting roughness and the angle of deflection of the pass marks. An increase in the $F_{c}$ force value during the cutting process may also be due to an increase in the jet deflection, but also due

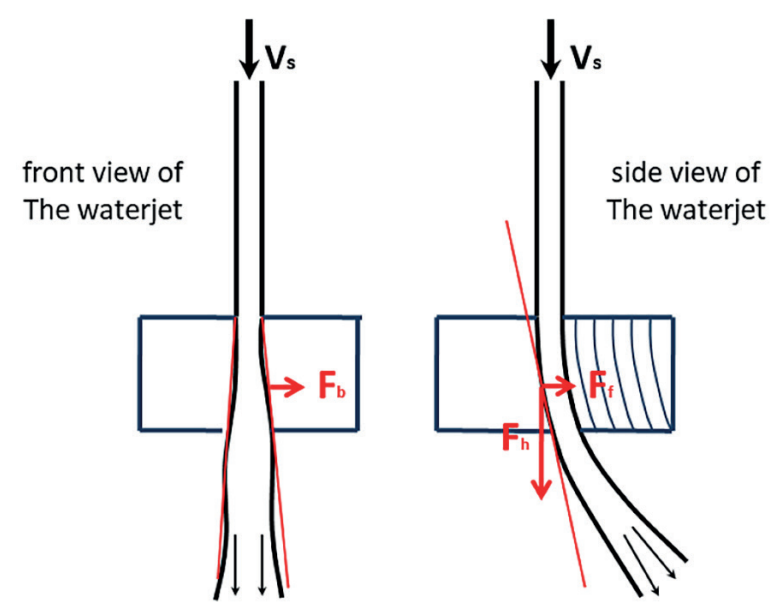

Fig. 2. View of reactions occurring on the waterjet during the workpiece cutting; $v_{s}$ - waterjet velocity, $f$ - direction of the waterjet feed velocity, $F_{f}$ - feed force, $F_{h}$ - indentation force, $F_{b}$ - side force [11]

to the jet power level depending on the set pump pressure. The value of the $F_{b}$ force should theoretically be close to zero, although it can also provide information about the convergence of the gap. It can be seen that monitoring these values can allow the surface quality to be controlled during actual water jet cutting.

In an experimental study, cutting tests were carried out on several materials with different mechanical properties using a Kistler 9272 force sensor (Fig. 3). A beam was bolted to the upper end and prepared specimens were clamped at the other end. The materials used for the tests were S235RJ and EN-AW-7075.

The example test results from force measurements for $20 \mathrm{~mm}$ thick specimens and S235RJ
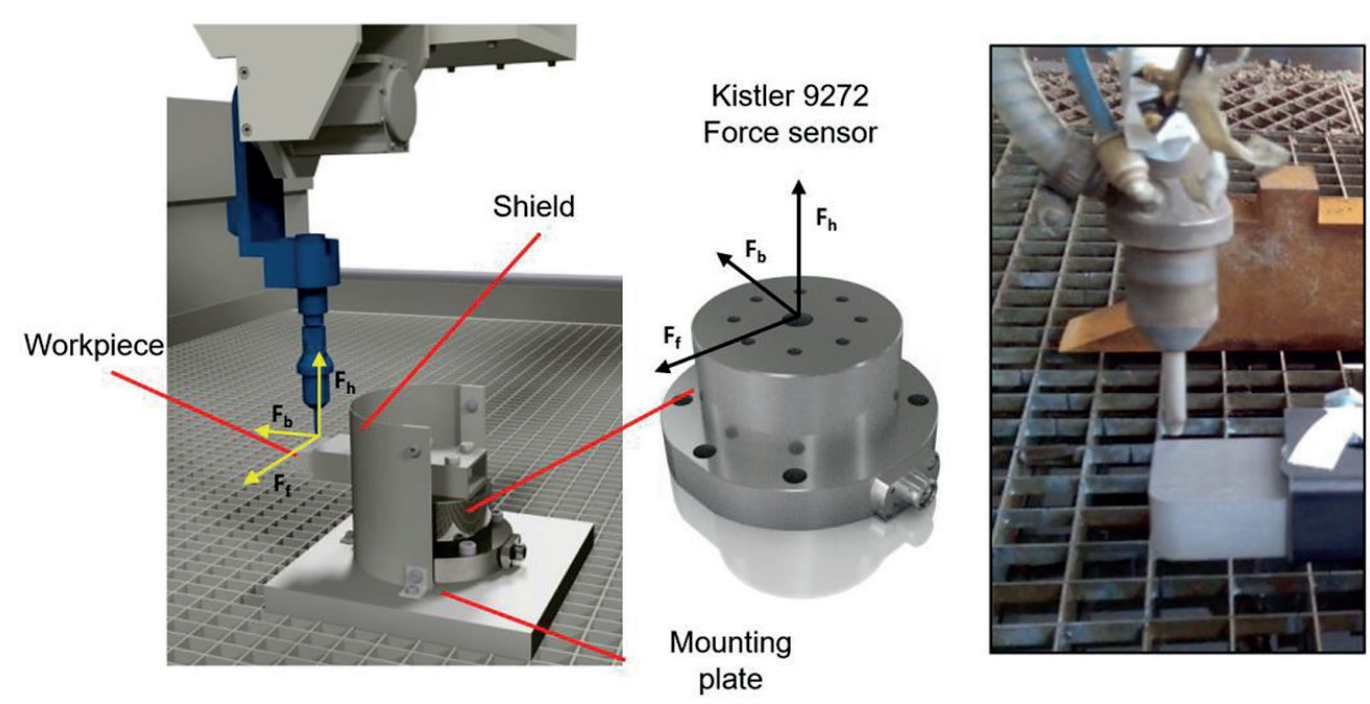

Fig. 3. View of measuring station 
and EN-AW-7075 materials are shown below Table 1 and 2.

The effect of the abrasive waterjet cutting head feed rate on the measured average forces is shown in Figures 4 and 5.

While analyzing the preliminary test results, it was noticed that the change in the value of the reaction force $F_{h}$ tends to increase for ever higher values of the feed rate. This force, similarly to the feed force $F_{f}$, is characterised by significantly higher values in relation to the lateral force $F_{b}$. Its increase was observed with an increase in the feed rate, which is due to the increasing resistance during the penetration into the workpiece. The

Table 1. Values of average reaction forces when cutting $20 \mathrm{~mm}$ thick aluminium EN-AW-7075

\begin{tabular}{|c|c|c|c|}
\hline $\begin{array}{c}\text { Feed rate } \\
{[\mathrm{mm} / \mathrm{min}]}\end{array}$ & $\begin{array}{c}\text { Force } F_{b} \\
{[\mathrm{~N}]}\end{array}$ & $\begin{array}{c}\text { Force } F_{f} \\
{[\mathrm{~N}]}\end{array}$ & $\begin{array}{c}\text { Force } F_{h} \\
{[\mathrm{~N}]}\end{array}$ \\
\hline 98 & 0.03 & 3.99 & 2.35 \\
\hline 137 & 0.57 & 3.93 & 2.34 \\
\hline 217 & 0.46 & 9.06 & 3.31 \\
\hline 304 & 0.12 & 10.57 & 9.46 \\
\hline
\end{tabular}

Table 2. Values of average reaction forces during cutting of $20 \mathrm{~mm}$ thick carbon steel S235RJ

\begin{tabular}{|c|c|c|c|}
\hline $\begin{array}{c}\text { Feed rate } \\
{[\mathrm{mm} / \mathrm{min}]}\end{array}$ & Force $F_{b}[\mathrm{~N}]$ & $\begin{array}{c}\text { Force } F_{f} \\
{[\mathrm{~N}]}\end{array}$ & Force $F_{h}[\mathrm{~N}]$ \\
\hline 24 & 0.13 & 3.88 & 1.3 \\
\hline 31 & 0.08 & 5.46 & 1.74 \\
\hline 43 & 0.22 & 7.38 & 3.65 \\
\hline 68 & 0.01 & 8.2 & 4.74 \\
\hline 96 & 0.44 & 8.99 & 7.62 \\
\hline
\end{tabular}

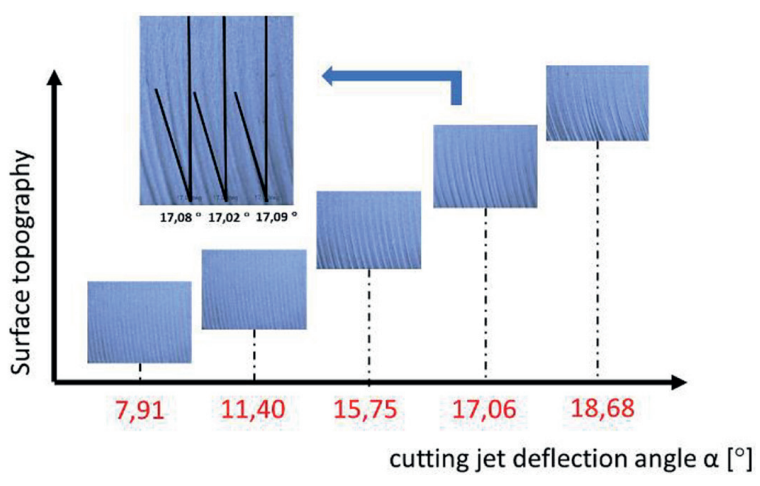

Fig. 5. Dependence of the force components on the change of the feed rate for aluminium EN-AW-7075

values of the regression coefficient for the force $F_{b}$ oscillate around the value of zero, which obviously means that this force does not depend on the value of the feed.

In a further stage of the study, measurements were made of the angle of deflection of the cut surface traces, for which the values of the cutting forces were measured. It was observed that there is a strong correlation between the values of forces and the angle of deflection of the machining marks. Figure 6 shows an example view of the topography of the cut surface depending on the feed rate. The angle value was measured as the slope angle of the tangent to the cut mark at the exit of abrasive waterjet from the workpiece.

Considering the reactions existing in the cutting area, it is possible to determine from the reaction equations taking into account the feed rate and waterjet velocity, the formula for the angle of deflection of the machining marks for the impact of

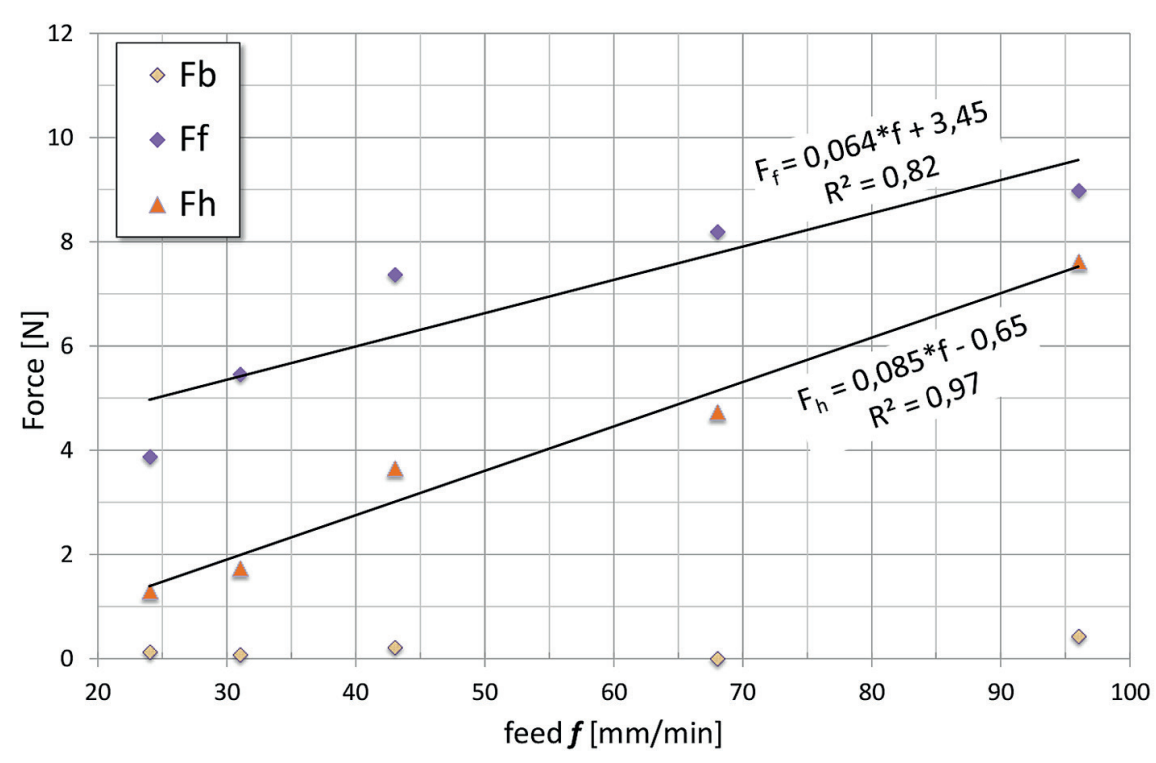

Fig. 4. Dependence of the force components on the change of the feed rate for carbon steel S235RJ 


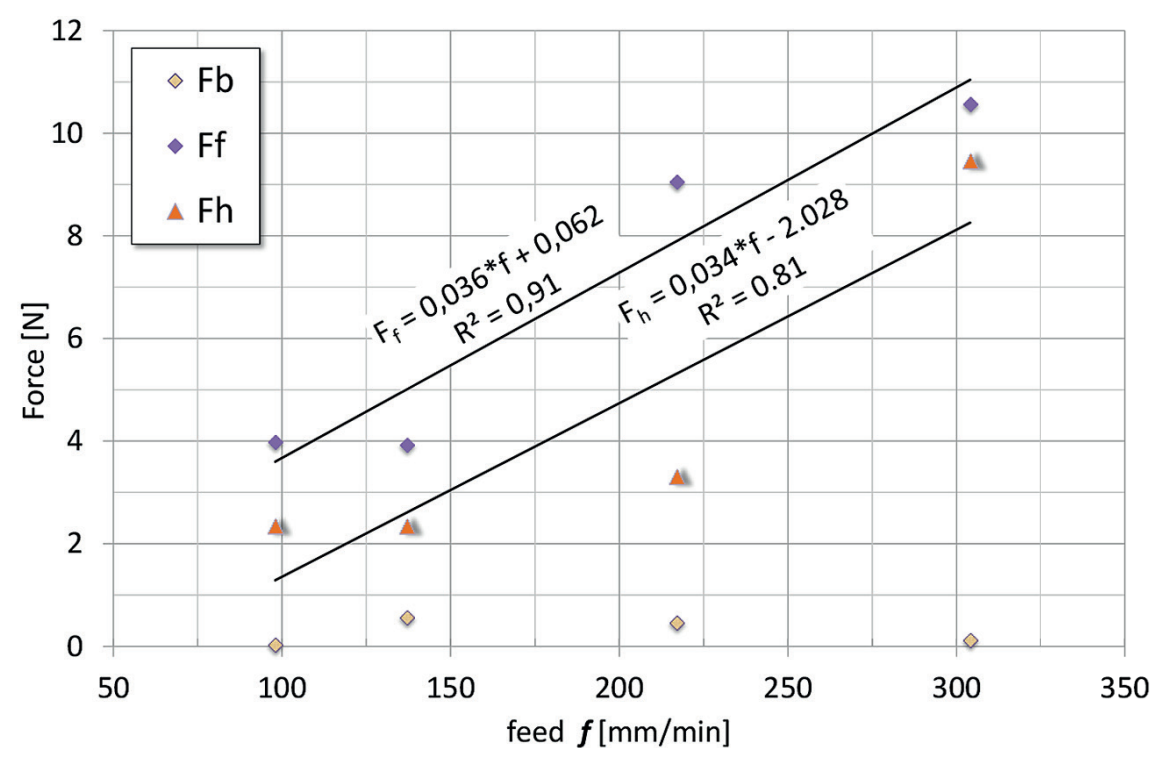

Fig. 6. Topography of the surface after cutting depending on the angle of inclination of the machining marks

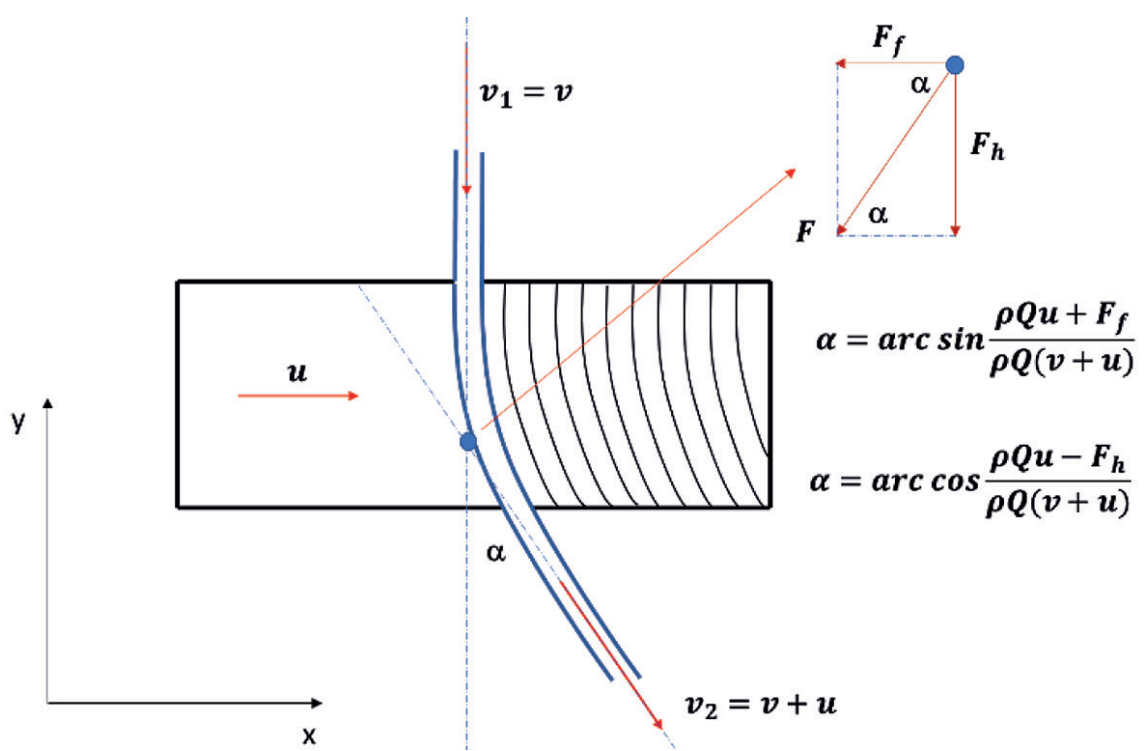

Fig. 7. Model of the angle of deflection of machining marks

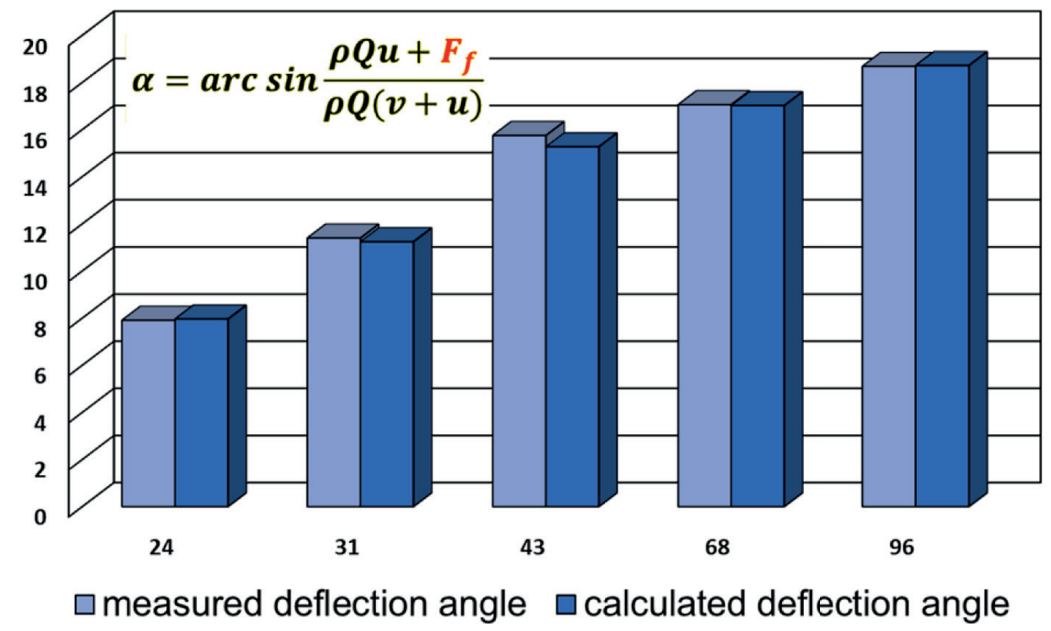

Fig. 8. Comparison of the measured values of the inclination angle of the machining marks with the values calculated from the angle model 

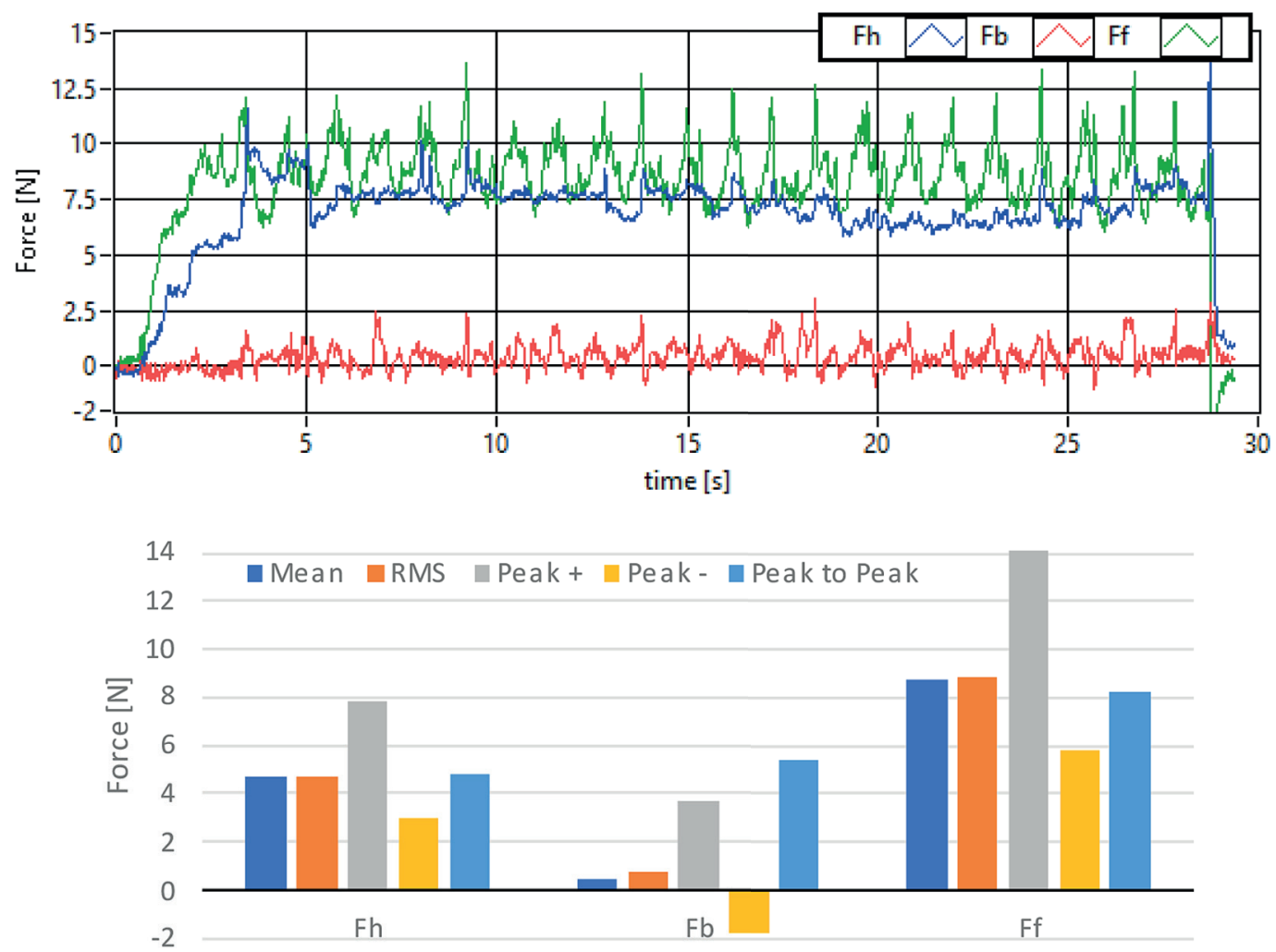

Fig. 9. Dependence of sensor indications as a function of force acting on the focusing tube tip in the direction of $F_{b}, F_{f}, F_{h}$. and their statistics. Parameters: S235RJ material, abrasive flow feed: $m_{a}=340 \mathrm{~g} / \mathrm{min}$, pressure: $p=330 \mathrm{MPa}$, feed speed: $f=90 \mathrm{~mm} / \mathrm{min}$

the feed force and axial force, respectively (Fig. 7). The method of identifying the jet deflection angle model is presented in the article by Wala et al. [12].

It was observed that the highest convergence of results occurs between the value of the striation angle and the measured feed force. Figure 8 shows a comparison of the striation angle measurements with the results obtained from the striation angle model for the selected material EN-AW-7075.

The determined model of the waterjet deflection angle (transition traces) based on the feed force has its justification in the fact that the force measured in the feed direction during the process has much higher values than the other forces. An example of the course obtained during the testing of force effects on the cutter head tip is shown in Figure 9 with statistic.

It should be noted that the disadvantage of this approach is that a specially designed workpiece clamping device must be used to measure the forces during the cutting process. Therefore, a further study presents the concept of measuring surface quality using vibration sensors mounted on the cutter head.

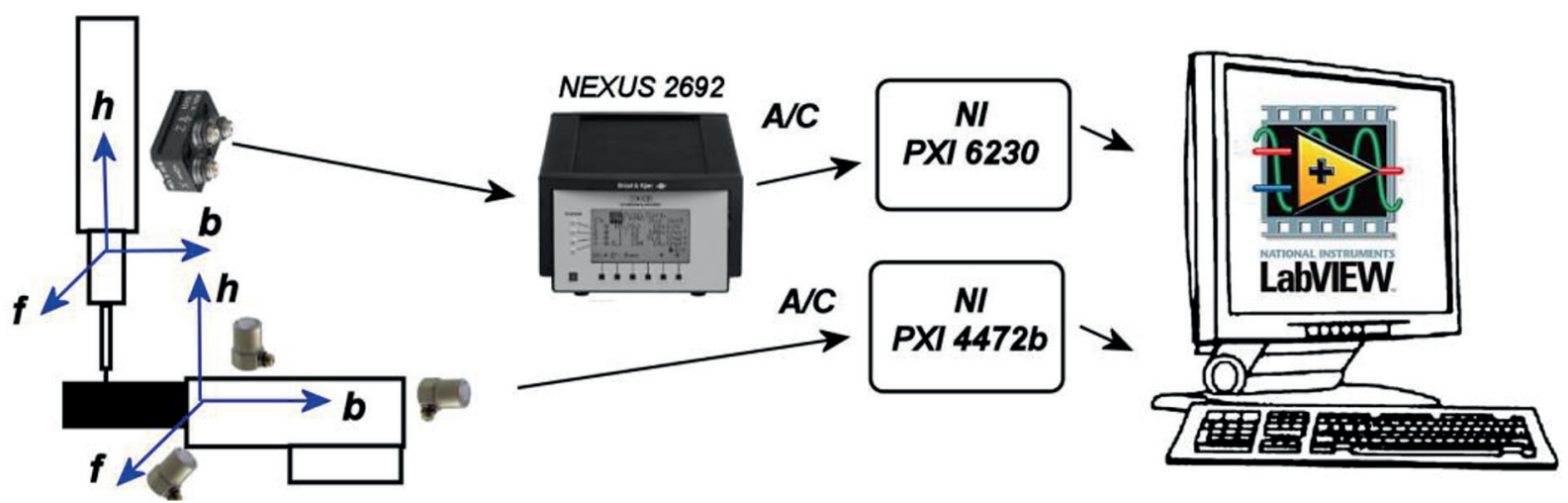

Fig. 10. Schematic of the measurement circuit 


\section{ASSESSMENT OF SURFACE ROUGHNESS USING VIBRATION SENSORS}

As part of the research on the evaluation of the surface quality, head vibrations were measured using a triaxial piezoelectric accelerator manufactured by Brüel \& Kjær, type 4326-A, which enabled the measurement of interactions in three mutually perpendicular directions. A schematic diagram of the measurement path is presented in Figure 10.

The test also followed the methodology of a previous study, in which specimens were mounted on a beam that allowed force actions to be measured from the side of the workpiece. Three piezoelectric sensors were mounted on the beam, each measuring vibration in a different direction. The concept of measuring vibration also from the workpiece side was to see how the cutting parameters affected vibration at the workpiece clamping point. Samples made of S235RJ carbon steel and EN AW-7075 aluminium alloy with different thicknesses were used in the experimental study.

As in previous studies, the values that were changed during the process were the feed rate. On the other hand, the values of pump pressure, abrasive flow rate were constant at $330 \mathrm{MPa}$ and 340 $\mathrm{g} / \mathrm{min}$, respectively.

To demonstrate the direct relationship between vibration and surface roughness, surface roughness height measurements were performed

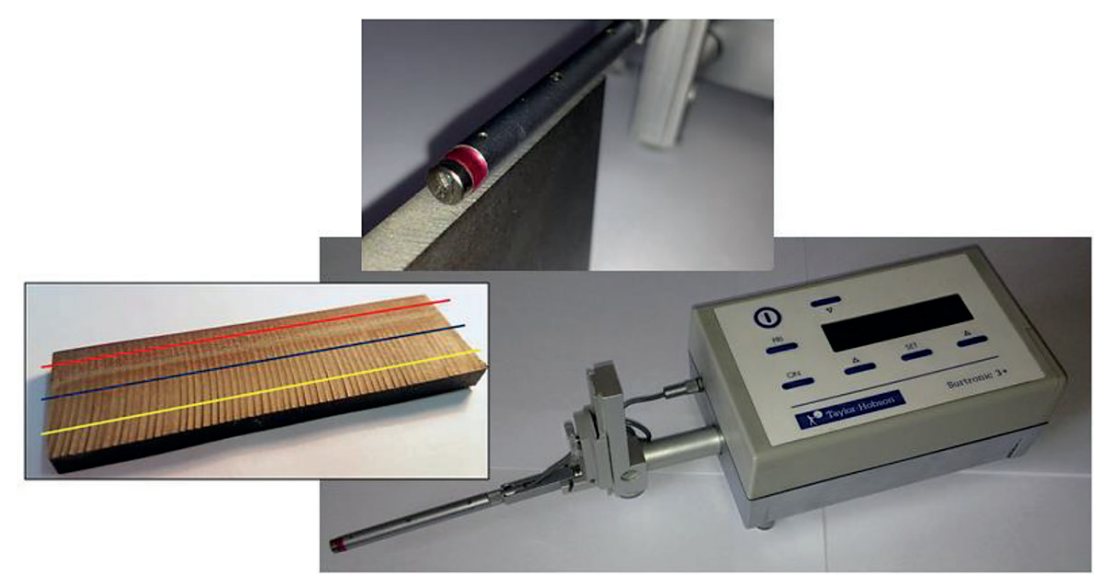

Fig. 11. Measurement of roughness height profile $R_{z}$
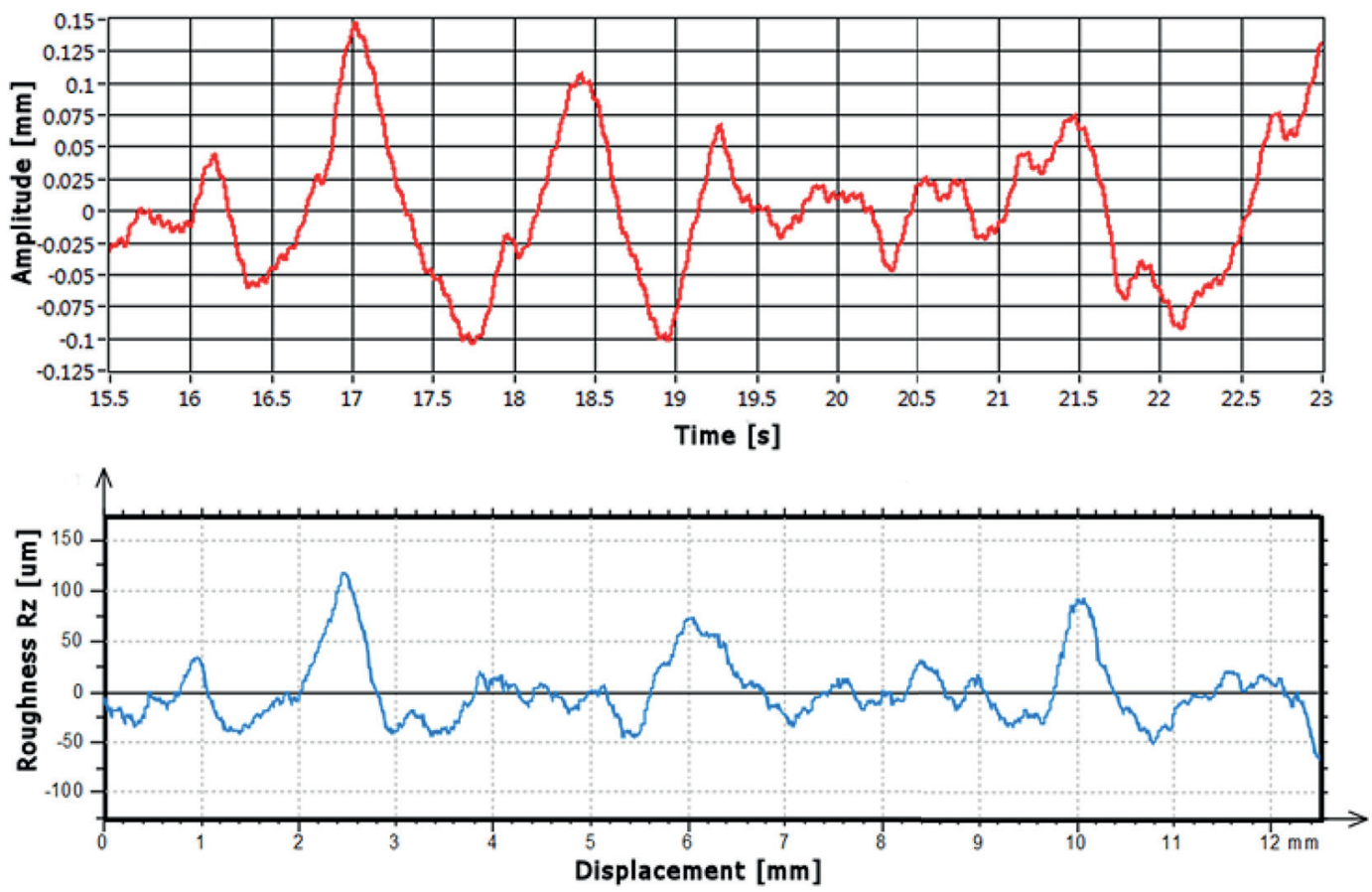

Fig. 12. Summary of Rz roughness with amplitude of displacement of cutter head, material sample: carbon steel S235RJ, thickness $20 \mathrm{~mm}$, feed rate $f=96 \mathrm{~mm} / \mathrm{min}$ [13] 
for each machined surface. Roughness height profile $\mathrm{R}_{\mathrm{z}}$ measurements were carried out in three different cross sections away from the top edge of the cutting surface - Figure 11.

Roughness height measurements were performed for a measuring length of $12.5 \mathrm{~mm}$. For these measurement lengths, runs of amplitude of displacement of the cutting head were matched for selected feed speeds.

Analysis of the graph of the roughness profile along with the head displacement showed that the highest points of the determined profile are related to the registered increased amplitude of the cutting head displacement. This shows that there is a close relationship between head displacement and the roughness of the workpiece cutting surface. The greatest convergence of the results of head displacement with the roughness profile was observed in the upper part of the cutting zone. The results of the juxtaposition of the height of roughness with the amplitude of cutting head displacement are presented below (Fig. 12).

\section{THE ADDITIONAL CONCLUSIONS FROM VIBRATION MEASUREMENTS}

In the course of the research, it was noted that the analysis of vibrations in the frequency domain may allow the control of additional process parameters such as pump pressure, abrasive flow rate.

The results obtained from the study of vibrations in the abrasive waterjet cutting process were analysed at different viewing angles. The analysis of vibration signals in the frequency domain was important for identifying the causes of vibrations in specific areas of the spectrum.

Example spectra of selected vibration courses of the cutting head at constant feed rate are presented below (Figs. 13 and 14). The colour of the spectrum indicates the direction of vibration measurement, where $b$ denotes the measurement of vibrations in the direction perpendicular to the cutting surface (cutting head feed direction), $h$ denotes the measurement of vibrations in the direction of the cutting stream axis perpendicular

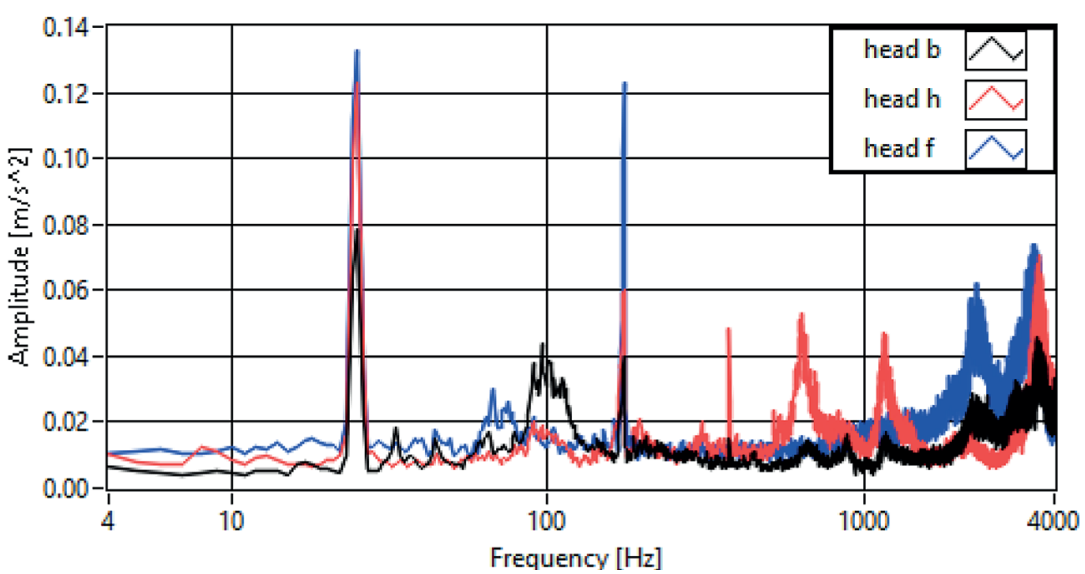

Fig. 13. Amplitude values of accelerations in frequency domain for cutting head determined during the conditions measurement: feed rate $f=137 \mathrm{~mm} / \mathrm{min}$, material: EN AW-7075 thickness $20 \mathrm{~mm}$

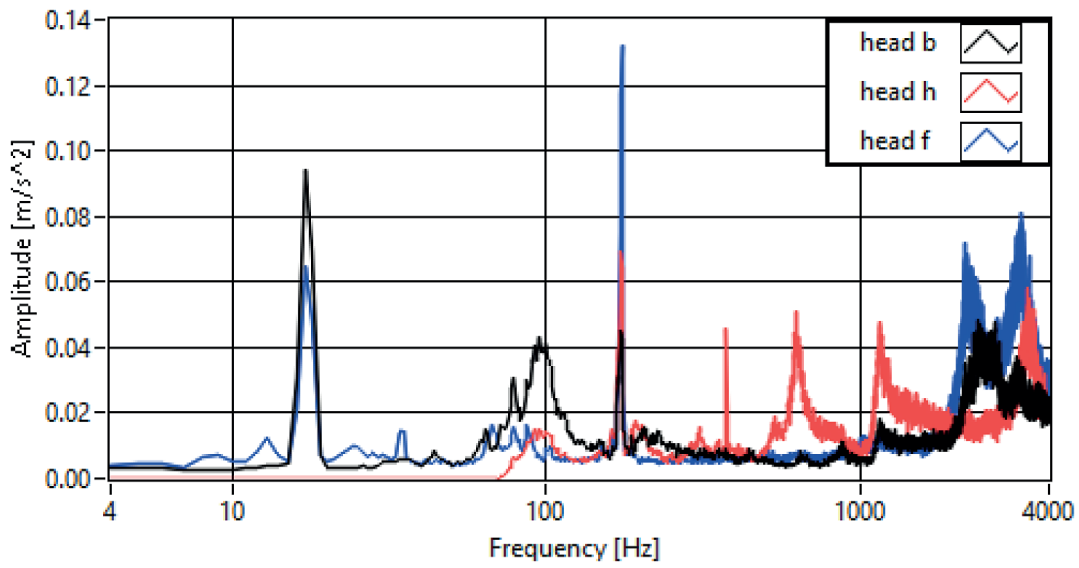

Fig. 14. Amplitude values of accelerations in frequency domain for cutting head determined during the conditions measurement: feed rate $f=137 \mathrm{~mm} / \mathrm{min}$, material: S235RJ thickness $20 \mathrm{~mm}$ 

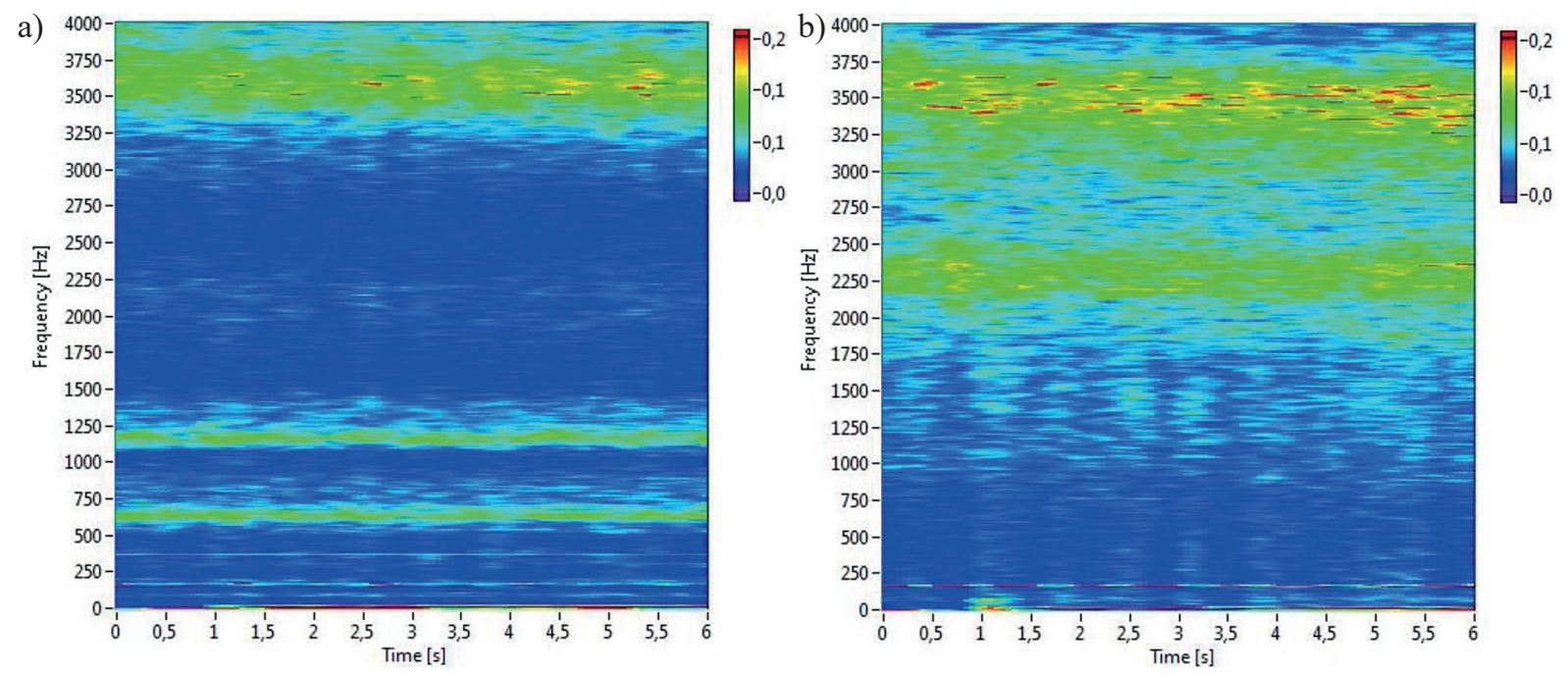

Fig. 15. Examples of an acceleration amplitude spectrogram for the feed rate $137 \mathrm{~mm} / \mathrm{min}$, material S235RJ: a) Gabor transformation determined in the direction of the force $F_{h}$, b) Gabor transformation determined in the direction of the force $F_{f}$ for the feed rate

to the workpiece surface, and $\mathrm{f}$ in the cutting head feed direction.

The realisation of the Fourier transform of the recorded signal with a sufficient number of samples entails the assumption of stationarity of the signal, which is difficult to achieve in the water abrasive cutting process. Therefore, within the framework of vibration identification, an analysis dedicated to time-varying signals, i.e. the Gabor transform, has also been applied. It is more beneficial for non-stationary signals obtained from vibration measurements occurring during the cutting process. This made it possible to determine for which frequencies the increased vibration amplitudes occurred and how they changed during the cutting of the samples. Figure 15 shows an example of an acceleration amplitude spectogram with the applied colour palette assigned to units of $\mathrm{m} /$ $\mathrm{s}^{2}$ in the direction of the cutter head axis and in the direction of the performed cut. The maximum vibration amplitudes are illustrated by the red area on the spectrogram.

It can be seen that the increased vibration amplitudes of the cutting head, always occur for five frequencies it is approx: $174 \mathrm{~Hz}, 376 \mathrm{~Hz}, 630 \mathrm{~Hz}$, $1150 \mathrm{~Hz}$ and $3430 \mathrm{~Hz}$. Analysing the vibration frequencies, it was found that the genesis of these vibrations is mainly related to the natural frequency of the specimens and their mounting. The amplitudes in the vibration frequency range 3410$3450 \mathrm{~Hz}$ increase with increasing abrasive flux intensity. Vibrations in the vibration frequency range around $200 \mathrm{~Hz}$ correspond to the operating frequency of the high pressure pump.

\section{MONITORING THE CUTTING PROCESS USING A STRAIN SENSOR}

Often, industrial strain sensors attached to a lowrigidity cutter head shank structure are used to detect cutting head collisions during the cutting process. The same sensor can be widely used to monitor deformation during the actual cutter head loads arising from the cutting process. The research developed the concept of using such a sensor to monitor the reaction forces arising during the cutting process. The sensor used was an ICP strain sensor from PCB - model $\mathrm{M} 240$ with a sensitivity of $50 \mathrm{mV} / \mu$. (Fig. 16).

The tests consisted in recording the forces acting on the tip of the focusing tube in correlation with the readings of the strain sensor, which was fixed in the head support structure. Examples of strain values measured during the cutting process are shown in Figure 17.

The process monitoring concept presented above is an attempt to use a specific sensor, such as a piezoelectric strain sensor, to evaluate loads and deformations of the cutter head and thus monitor the behaviour of the cutting head during the cutting process under industrial conditions. The values of the measured forces contain important diagnostic information from the point of view of the deflection of the cutting head during cutting as described above.

\section{CONCLUSIONS}

The above-mentioned tests are a synthesis of the research carried out earlier in terms of the possibility 


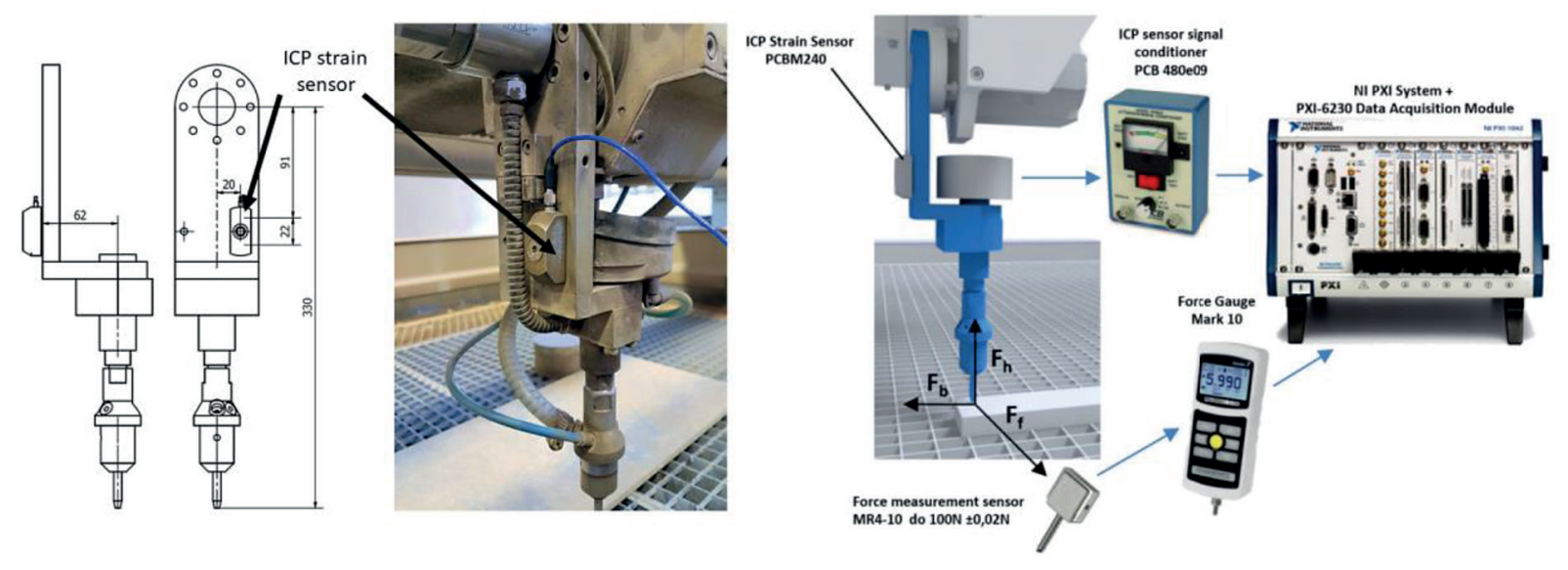

Fig. 16. The way of mounting the deformation of cutter head sensor in the supporting structure of the AWJ machine [14]
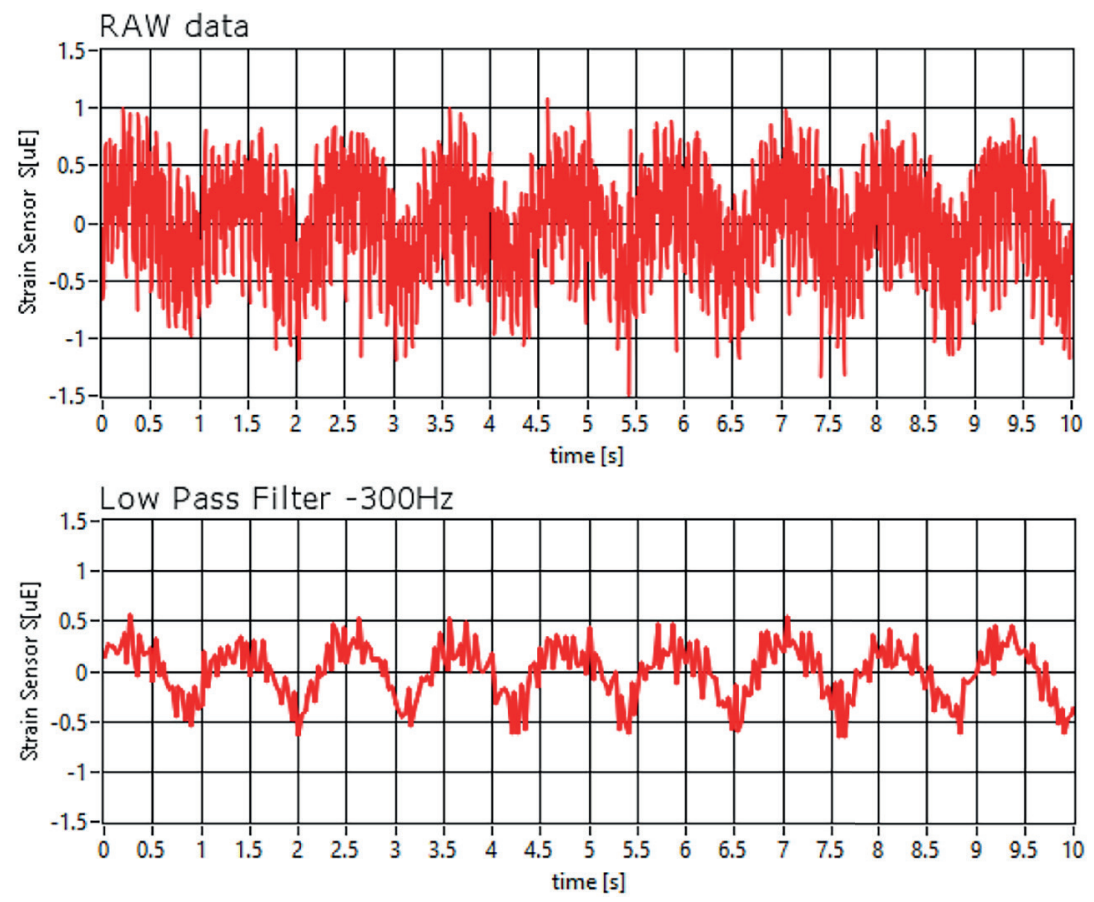

Fig. 17. The strain values measured during the abrasive waterjet cutting process; the feed rate $137 \mathrm{~mm} / \mathrm{min}$, material S235RJ [14]

of monitoring the cutting process in order to obtain the correct cutting surface using the abrasive waterjet machining method. The essence of these tests is to determine such features of the recorded signals that on their basis it is possible to correct the cutting conditions in the actual machining mode in order to obtain the correct surface quality.

Measurement of the component forces during the cutting process allows control of the angle of deflection of the abrasive waterjet cutting, which leads to the possibility of controlling the surface roughness of the cut during the process. Research proves that an important force in the cutting zone is the feed force, which enables control of the surface topography.
The concept of investigating cutting interactions based on the use of vibration sensors makes it possible to monitor the operation of the hydraulic system, mainly the operation of the pressure pump, based on the values of the pump vibration frequency measured by sensors mounted on the cutting head.

Analysis of vibrations in the amplitude domain showed that the method allows control of the abrasive flow by recording maximum amplitudes during the process.

During vibration analysis, some correspondence was observed between the cutting head displacement results and the roughness profile measured at 
the top of the cutting zone, which may also allow control of the maximum roughness height value.

Studies using strain sensors have shown that this is another alternative for measuring the forces in the cutting zone to monitor the deflection of the waterjet during the cutting process.

\section{Acknowledgements}

This work was financed from the funds of the Ministry of Education and Science by Agreement No. DNK/SP/513880/2021 of 22 December 2021, the project " $14^{\text {th }}$ School of Machining and the $43^{\text {rd }}$ Scientific School of Abrasive Machining", under the programme "Perfect Science".

\section{REFERENCES}

1. Pillai S.R., Madara S.R., Selvan C.P. Predication of Kerf Width and Surface Roughness in Waterjet Cutting using Neural Networks. International Conference on Recent Advances in Fluid and Thermal Sciences. Journal of Physics: Conference Series. 2019; 1276: 012011.

2. Kovacevic R. Monitoring the depth of abrasive waterjet penetration. Internationa Journal of Machine Tools and Manufacture. 1992; 32(5): 725-736. https://doi.org/10.1016/0890-6955(92)90026-D

3. Lin B., Zou Q., Liang Y., Xie J., Yang H.: Response characteristics of coal subjected to coupling static and waterjet impact loads. International Journal of Rock Mechanics and Mining Sciences. 2018; 103: 155-167.

4. Carah J., Lehocka D., Legutko S. Hloch S., Chattopadhyaya S., Dixit A.R. Surface roughness of graphite and aluminium alloy after hydro-abrasive machining. Advances in Manufacturing (Manufacturing 2017), Edited by: Hamrol A., Ciszak O., Legutko S., Jurczyk M., Book Series: Lecture Notes in Mechanical Engineering. 805-813. https://doi. org/10.1007/978-3-319-68619-6_66

5. Copertaro E., Perotti F., Castellini P., Chiariotti P., Martarelli M., Annoni M.: Focusing tube operational vibration as a means for monitoring the abrasive waterjet cutting capability. Journal of Manufactur- ing Processes. 2020; 59: 1-10.

6. Kovacevic R., Wang L., Zhang YM. Identification of abrasive waterjet nozzle wear based on parametric spectrum estimation of acoustic signal. Proceedings of the Institution of Mechanical Engineers, Part B: Journal of Engineering Manufacture. 1994; 208(3): 173-181. https://doi.org/10.1243/ PIME_PROC_1994_208_076_02.

7. Hassan Ashraf I., Chen C., Kovacevic R.: On-line monitoring of depth of cut in AWJ cutting. International Journal of Machine Tools and Manufacture. 2004; 44(6); 595-605. https://doi.org/10.1016/j. ijmachtools.2003.12.002.

8. Valíček J., Hloch S. Using the acoustic sound pressure level for quality prediction of surfaces created by abrasive waterjet. International Journal of Advanced Manufacturing Technology. 2010; 48: 193203; https://doi.org/10.1007/s00170-009-2277-3

9. Peržel V., Hreha P., Hloch S., Tozan H., Valíček J.: Vibration emission as a potential source of information for abrasive waterjet quality process control; International Journal of Advanced Manufacturing Technology. 2012; 61: 285-294. https://doi. org/10.1007/s00170-011-3715-6

10. Jurisevic B., Brissaud D., Junkar M. Monitoring of abrasive water jet (AWJ) cutting using sound detection. International Journal of Advanced Manufacturing Technology. 2004; 24: 733-737. DOI 10.1007/s00170-003-1752-5

11. Wala T., Lis K. The study of forces interactions during the high pressure abrasive waterjet cutting. 2015; 8-9: 415-423.

12. Wala T., Lis K. The experimental method of determining the forces operating during the abrasive waterjet cutting process - a mathematical model of the jet deviation angle. Industrial measurements in machining. Eds. Grzegorz M. Królczyk, Piotr Niesłony, Jolanta Królczyk. Springer. 2020; 236-245. https:// doi.org/10.1007/978-3-030-49910-5_21

13. Wala T., Lis K. The vibration measurements during the abrasive waterjet cutting for the evaluation of surface quality. Mechanik. 2016; 8-9: 1084-1085.

14. Lis K., Wala T. Experimental research possibilities of monitoring the AWJ cutting process using a strain sensor. International Journal of Modern Manufacturing Technologies. 2020; 12(3): 72-77. 